\title{
Lateral
}

Journal of the Cultural Studies Association

\section{Review of Gestures of Concern by Chris Ingraham (Duke University Press)}

\begin{abstract}
by Nicole Dib | Book Reviews, Issue 10.1 (Spring 2021)
ABSTRACT Chris Ingraham's Gestures of Concern considers how affective communities can be built by and through concerned gestures. His analysis of the political power of a range of these gestures-from the small tokens of get-well cards to the political protests against shuttered public resources such as librariesemphasizes their affect as much as their action. Ingraham pays attention to the background of concerned gestures that are political, aesthetic, and communitybased, and his analysis of their efficacy and their impact draws readers to consider different kinds of critical resistance in the face of growing social disparities.
\end{abstract}

KEYWORDS aesthetics, affect theory, culture, political participation, politics

Gestures of Concern. By Chris Ingraham. Durham: Duke University Press, 2020, 264 pp. (paperback) ISBN: 978-1-4780-0951-1. US List: \$26.95.

In Chris Ingraham's keen and hopeful Gestures of Concern, the titular gestures are the means by which people engage with public life. Ingraham analyzes the seeming inconsequence of various gestures to demonstrate that they are, in fact, affectively generative, and that they have the potential to create togetherness in the lives of increasingly marginalized and precarious subjects. These gestures prime us, Ingraham argues, for political change in order to help this change take hold. His work demonstrates how the daily, creative-and often unnoticed-work of building an "affective commonwealth," one of the ideas most heavily discussed in the book, can lead to positive political change for underserved communities in US and Western European contexts.

Despite the promises of contemporary participatory culture Ingraham outlines-the tweets, the Occupy movements, the posts that are part and parcel of social mediacommunicative participation in the world does not lessen the felt impact of the calamities and disparities that rage around us. One of the goals of Ingraham's study is to consider how concerned gestures are affectively generative and can help address feelings of exclusivity that are still present and growing despite the world's increasing connectivity through technology, social media, and participatory political culture. His keen emphasis on resisting the present (the very goal of critical theory) while affirming gestures as a way to cultivate "a sense of interdependence and connectivity" gives his study a cautious and qualified optimism (6). This very sense emerges in one of his most compelling concepts outlined in the introduction, that of the "affective commonwealth" which refers to "a shared sense of what it feels like to be alive at the present time, but as if that feeling were a resource anyone could draw on to make sense of their worlds and to affirm more sustainable ways of being interconnected within them" (5). 
Ingraham's approach melds political theory, communication and media studies, and affect theory together with a dose of rhetorical concerns in three sets of paired chapters bookended by an introduction and an epilogue. Chapters one and two outline and discuss those foundational concepts of concern and gestures. Unlike physical gestures, what Ingraham calls "gestures of concern" are expressions in the form of an affective relation; these gestures can include language, gifts, artwork, etc., but, as his "Get Well" card example demonstrates, "what they share is an expressive concern that acts as both a means and as an end because their most instrumental effects are exhausted in their expressivity" (1). Ingraham is careful to frequently differentiate what gesture means for his book, in contrast to the more commonly associated bodily definition. Ingraham's gestures are best defined in the many examples he provides, ranging from the afore-mentioned "Get Well" card, to the act of saying Gesundheit when someone sneezes, and the "liking" of a post on social media. In the eventual turn to larger, often more community-based or communal gestures that Ingraham studies in the later chapters, his statement about the affective force of these gestures is particularly exigent: that this force "affirms a sense of something more intangible. Call it kinship, empathy, solidarity, kindness. In this book, I call it concern" (52).

In the book's second pairing of chapters, Ingraham troubles the divide between "art" and "real life" and points to the increasingly blurred lines between other social and aesthetic dichotomies including the virtual and actual, or the artist and audience. His greater argument in these chapters is that "attending to concerned gestures, along with the interplay of affective and symbolic orders, suits the dynamics of a contemporary culturescape that finds citizen artists and critics working in tandem, but also in tension" (80). The strength of Ingraham's discussion is his consistently balanced survey of how such divides emerged and remain today (including the divide between professional and amateur artist, for example, and the gap between public and private). There is a balance between a history of aesthetics and artistic reception coupled with Ingraham's own theoretical contribution in the form of his attention to concerned gestures; in these paired chapters on art and artists, this approach covers topics ranging from curatorship to algorithmic culture's effect on artistic production. This balance makes Ingraham's work especially helpful for readers who want significant analysis of contemporary topics in artistic and cultural production along with a discussion of the affective results of technological changes in art. Ingraham's discussion of the participatory nature of Goodreads, for example, blends his theoretical interest in affect and identification with a fascinating reading of the potentially harmful results of algorithmic participation on authors featured on the website.

In what feels like Ingraham's most optimistic final pairing, chapters five and six turn to the building of affective commonwealths which have the potential to contribute to "a shared attunement and response-ability to one another" (131). This hopeful sense comes from Ingraham's analysis of an especially heartbreaking example of the impact of concerned publics: public library closures proposed and enacted in various British cities around 2010. Linking the peril of public libraries in the United Kingdom to other practices of social exclusion in Europe, Ingraham studies performative acts of resistance including a "Wall of Shame" in the London Borough of Brent that reproached the Brent Council's decision to close their libraries, as well as a pop-up library built and staffed by ordinary citizens. The pop-up library in particular exemplifies the significance of Ingraham's own theory of concerned gestures by ordinary citizens: "affirming a sense of community in this is what creates, again and again, an actual community" (159, emphasis in original). Calling attention to these acts of artistic, cultural, and political creation demonstrate the impact of 
participation itself, even and especially in venues that are less visible, publicized, or professionalized.

Ingraham's wide-ranging engagement with rhetoric, artistic production, political engagement, and participatory culture makes his book of interest to those readers attracted to an interdisciplinary approach to cultural studies. For readers interested in literary studies, there are ample moments where Ingraham's cultural studies approach is bolstered by deeply detailed close readings. The book's epilogue demonstrates this approach, as it engages with the poet W.H. Auden's 1962 essay entitled "The Poet and the City" through a set of close readings and innovative rebuttals regarding Auden's own concern about the forces preventing artists from pursuing their work. Ingraham walks through four of Auden's beliefs in connection to this problem and provides his own Anthropocene-minded modifications. Auden's argument that "the loss of belief in the eternity of the physical universe" could be a reason for an artistic slowdown, for example, is modified by Ingraham's own assertion that "[a] growing belief in the physical universe's power to outlast the human" has raised the stakes for artistic and political intervention (188-189). Closing his book with this series of challenges to political, communicative, artistic, and, of course, gestural engagement with the world continues to model the reading practice that Ingraham had been demonstrating throughout Gestures of Concern, one that defines the world in practices of care and concerned gestures.

\section{Author Information}

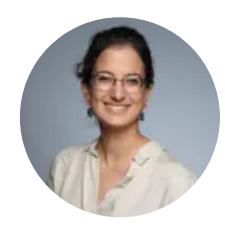

$\underline{\text { Nicole Dib }}$

Nicole Dib is an Assistant Professor in the English department at Southern Utah University. She specializes in contemporary American literature, comparative ethnic approaches to literary studies, critical race studies, and road-trip narratives. Her teaching and research intersect several fields in the humanities, drawing from literary studies, cultural studies, mobility studies, and ethnic studies. Her scholarly work appears or is forthcoming in MELUS: Multiethnic Literature of the United States, Feminism and Comics: New Essays on Interpretation, The Routledge Companion to Critical Masculinity Studies, and Teaching the Classics in the US Prison System.

View all of Nicole Dib's articles.

\section{Article details}

Nicole Dib, "Review of Gestures of Concern by Chris Ingraham (Duke University Press)," Lateral 10.1 (2021).

https://doi.org/10.25158/L10.1.32

This content is licensed under a Creative Commons Attribution-NonCommercial 4.0 International 
License. Copyright is retained by authors.

Lateral is the peer-reviewed, open access journal of the Cultural Studies Association.

ISSN 2469-4053 